\title{
GOBIERNO COLONIAL Y GOBIERNO CONVENTUAL, JERARQUÍAS Y REDES SOCIALES. UNA MIRADA A LA SOCIEDAD CHARQUEÑA Y AL MONASTERIO DE NUESTRA SEÑORA DE LOS REMEDIOS DE SANTA MÓNICA DE LA CIUDAD DE LA PLATA, 1574-1600
}

\author{
COLONIAL AND CONVENTUAL GOVERNMENT, HIERARCHIES, AND SOCIAL \\ NETWORKS. A GLANCE TO CHARCAS SOCIETY AND THE MONASTERY \\ OF NUESTRA SEÑNORA DE LOS REMEDIOS DE SANTA MONICA \\ DE LA CIUDAD DE LA PLATA, 1574-1600
}

\author{
Ana María Presta*
}

\begin{abstract}
La sociedad colonial, réplica de la metropolitana, reunió a actores diversos y creó nuevos otros dentro de una jerarquía social inscripta en el cuerpo de la monarquía católica. Para mantenerse en la cúspide, la novel elite charqueña, que distaba de pertenecer al estado nobiliario aunque lo emuló al constituirse como tal, legitimó sus vínculos primarios y pretendió una estabilidad demográfica que asegurara su sostén patrimonial. En ese orden, la creación de un convento pretendió inhibir la onerosa partición patrimonial generada por matrimoniar a varias de sus descendientes mujeres. En esta investigación exponemos la réplica gubernamental del siglo a nivel conventual y, tras varios eventos que involucraron a las monjas en situaciones judiciables, observamos cómo las instituciones administraban el derecho conforme con los estados o personas.
\end{abstract}

Palabras claves: gobierno colonial, elite, monjas, justicia, derecho.

Colonial society, as a replica of the metropolis, reunited diverse actors and created new others as well within a social hierarchy printed in the body of the Catholic monarchy. In order to be maintained at the top, the new elite of Charcas, which was far to belong to the nobility it emulated, legitimized its primary bonds keeping, at the same time, demographic stability that ensured its wealth and belongings. In so doing, a convent was the means to avoid the dramatic split of the patrimony that could happen if several daughters were to be married. This research tries to picture the governmental replica at the convent level while presenting a series of events that involved the nuns in judicial situations. In so doing, we observe how the institutions administered law according to different states and persona.

Key words: colonial government, elite, nuns, justice, law.

\section{Introducción}

\section{Contexto y consideraciones historiográficas iniciales}

Al arribar a la intersección de las calles Arenales y Junín de la ciudad de Sucre, el viajero no deja de admirar una imponente iglesia colonial. Nívea e impactante en su factura, como los restantes monumentos históricos que ameritaron designar a la ciudad como Patrimonio de la Humanidad por la UNESCO, la iglesia a la que aludo se construyó en la década de 1580 en la entonces ciudad de La Plata, hoy Sucre, capital histórica del Estado
Plurinacional de Bolivia, también nombrada Charcas o Chuquisaca, sede de la Real Audiencia homónima. Los chuquisaqueños suelen nombrar al silente monumento "las Mónicas", quizás sin saber que se trata del templo del Monasterio de Nuestra Señora de los Remedios que, bajo la advocación de Santa Mónica y la supervisión religiosa de la Orden de San Agustín, fundó la elite platense en 1574 para depositar a las huérfanas hijas de conquistadores, a sus hijas con vocación pero, sobre todo y aunque de manera inconfesa, a aquellas descendientes que había decidido no casar ${ }^{1}$. Activo por 350 años, el cenobio sobrevivió al decreto de secularización republicana de 1826 emanado del Libertador Simón

\footnotetext{
* Consejo Nacional de Investigaciones Científicas y Técnicas (CONICET) - Programa de Historia de América Latina (PROHAL), Instituto de Historia Argentina y Americana “Dr. Emilio Ravignani”, Facultad de Filosofía y Letras, Universidad de Buenos Aires. Dirección postal: 25 de Mayo 221, 2do. Piso. Ciudad Autónoma de Buenos Aires (1002), Argentina. Correo electrónico: ampresta@filo.uba.ar; amprestaar@yahoo.com
} 
Bolívar con un puñado de monjas (Berríos 1909:11), hasta que a inicios del siglo XX lo que quedaba de su predio e iglesia se incorporaron a la Compañía de Jesús y a su colegio Sagrado Corazón.

Para quien estudia su vida interior y, sobre todo, sus prolongaciones y vínculos externos, este templo y su pórtico enrejado constituyeron la puerta de ingreso a un territorio acotado, uno más de los estados corporativos coloniales aunque, a diferencia de los demás, se definía por el género, en tanto el convento femenino estipulaba el enclaustramiento, condición que solo aplicaba a las mujeres (Lavrin 2008:8).

Interpretados linealmente, los conventos femeninos se prefiguran como ciudades fundadas dentro de otra, lo que sugiere un falso aislamiento. Estimo que Los Remedios fueron una corporación con reglas propias habitado por monjas de velo negro o de coro, de velo blanco, novicias, hermanas laicas o donadas y mujeres casadas en vías de separación, en custodia o depósito. La mayoría permanecía en el claustro para siempre aunque en compañía de parientes, esclavos y sirvientes, manteniendo una profusa sociabilidad jerárquica detrás del locutorio, refectorio, rejas, puertas selladas y cortinas engañosas que desafiaban los frágiles muros.

A pesar de abordar a las monjas y su convento, mi propuesta no se asienta en las prácticas religiosas. Mi interés y compromiso radican en el mundo profano y, por esta razón, desde una perspectiva social y de género, persigo las variables y fundamentos de la dominación y el ejercicio del poder en la larga duración. De allí mi propuesta de observar la producción y reproducción de instituciones que a lo largo de los siglos coloniales concentraron las relaciones de poder y replicaron las desigualdades sociales. El convento, como creación de quienes por vecindad y valores habían fundado sus "casas pobladas" y linajes constituyéndose como elite luego de acceder a mercedes, honores y específicas funciones de gobierno, iba a reflejar esas desigualdades junto con las prácticas y representaciones señoriales que lo distinguían como a otra de las corporaciones caracterizadas por su gobierno vertical y autónomo, desde donde sus autoridades resolvían problemas internos aunque asociados a los temas políticos, sociales y económicos de un "siglo" que era el afuera pero que incidía y resonaba adentro ${ }^{2}$.

Con el fin de mensurar cuánto de la organización conventual se parangonaba con la secular y de qué manera esta influenció sus reglas, organización, prácticas y convivencia, recupero un conjunto de episodios que cristalizaron en 1590 y exhiben las prácticas y representaciones corporativas de las monjas junto con el ejercicio del poder de sus autoridades. Por medio de esos episodios, que culminan en un conflicto que toma estado público y en el que intervienen las monjas y sus familiares, numerosos actores religiosos, oidores de la Real Audiencia y cabildantes, abiertamente o en las sombras, se devela la corporación conventual, sus valores y prácticas junto con sus espejos normativos y valorativos. Pero antes de llegar a ello, la misma fundación de Los Remedios y sus avatares ligan a la institución a otras no menos notables y generadoras de las relaciones sociales coloniales: la encomienda y la familia.

\section{La elite charqueña, sus instituciones y el diseño social}

En su carácter de institución medieval remodelada al servicio de la dominación colonial, la encomienda contenía la matriz que diseñó y prolongó las relaciones sociales en la larga duración (Barnadas 1973:215-216; Presta 2000, 2013:107-109). Más allá de su condición de merced real que confería el derecho de percepción del tributo de un conjunto determinado de indígenas para su tenedor y sucesor legítimo, la encomienda satisfacía las aspiraciones señoriales del conquistador pues, en su condición de señor de vasallos y vecino, debía servicio militar al rey y, al mismo tiempo, desempeñaba oficios representativos en el régimen municipal de gobierno (Presta 2000:3-7). Los encomenderos de La Plata distaban de tener ascendencia noble y, aunque se preciaran de hidalgos, solo tres de ellos ostentaban el "don" en la década de $1570^{3}$. Sin embargo, por virtud del servicio prestado al rey se convirtieron en elite colonial y, conforme con ello, emularon ideales caballerescos, militares y señoriales, a la vez que exacerbaron y alardearon de valores como el honor, la buena fama y la gloria sumada a la condición de beneméritos por el triunfo en la gesta de conquista. Al igual que los nobles peninsulares, los encomenderos se obsesionaron con la genealogía y la descendencia, esforzándose por fundar linajes que mostraran su reciente adquisición de riqueza y estatus junto con el intento de cimentarlos y transferirlos a futuras generaciones. De allí que los señores de indios debían casarse para traspasar su merced a un heredero legítimo. No obstante ello, numerosos encomenderos de la primera generación, 
recompensados por Francisco Pizarro entre 1535 y 1540 , ya fuera por ausencia de mujeres españolas o por razones amorosas cuyo compromiso prejuicioso inhibía la formalización del vínculo, tenían concubinas indígenas y unos pocos estaban casados legítimamente con peninsulares o mestizas. Hacia 1550 el mestizaje era una realidad palmaria y los hijos mestizos de los conquistadores proliferaban en todas las jurisdicciones. Las mestizas, si reconocidas por sus padres beneméritos, habitando en sus casas y educadas en los valores, cultura y religión cristianos, tenían la posibilidad de borrar el estigma de nacimiento, la ilegitimidad o la nombrada "imperfección genealógica", asegurando su inclusión en la elite e ingresando al mercado matrimonial como si fueran españolas (Martínez 2008:61-70, 82-85). Por virtud de la sangre y el "señorío" de sus padres, las mestizas ganaban estatus a pesar de su mezcla, la que, razones explicitadas mediante, se volatilizaba, fundía, borraba y barnizaba rápidamente.

A causa de este contexto ideológico, la autoridad del patriarca o cabeza de familia resultaba crucial para salvaguardar la sucesión y transmisión de la propiedad, en conjunción con el fantasma de la limpieza de sangre, factor omnipresente en el momento de fundar una familia o reforzar las alianzas. Luego de la finalización de las Guerras Civiles entre facciones de españoles (1538-1548), la efímera e inicial generación de encomenderos resultó renovada. Numerosos encomenderos murieron durante las guerras y sus vastas mercedes fueron divididas con el fin de proveer más y nuevas encomiendas para recompensar a quienes se habían mantenido leales al rey. Conscientes de que su merced solo podía transferirse a un heredero legítimo, esta nueva generación de encomenderos desplegó cuidadas estrategias matrimoniales y construyó redes familiares que reflejaron la meditada elección de pareja conforme con las jerarquías sociales peninsulares, buscando constituirse en elite de larga duración. El patriarcado junto con el matrimonio y la sucesión estaban inscriptos en el habitus, ya que respondían a las normas y disposiciones reguladas y reforzadas por la costumbre y la ley (Bourdieu 1977:73, 1979:189-197, 1980:52-65). A pesar de no estar reglamentado jurídicamente, el matrimonio entre iguales era el vehículo de la reproducción de las jerarquías sociales dentro de la elite (Chacón Jiménez y Martínez López 1990:33-35; Bestard Camps 1992; Comas D'Argemir 1992). Un matrimonio apropiado era indispensable para reproducir una sociedad que, edificada en una suerte de "ficción genealógica", enfatizaba la tenencia real o imaginaria de pedigrí, la procedencia de cristianos viejos y la posesión del honor como valores fundamentales e indispensables para que un individuo fuera considerado, en el lenguaje del siglo XVI, puro y hasta "lindo", todo ello se transmitía por la sangre (Martínez 2008:47-50).

Mis estudios previos referentes a la elite de Charcas me permiten concluir que los nuevos linajes encomenderos fueron notablemente prolíficos. $\mathrm{Si}$ la fertilidad resultaba en criar varias hijas mujeres, el pater familias disponía a cuántas casaría, demostrando no solo la autoridad ejercida sobre la prole sino también las diferencias internas dentro del hogar familiar. Los linajes coloniales procedían de nuevas fortunas, las que debían permanecer compactas e indivisibles con el fin de transferirse a las futuras generaciones. Casar a una hija con el candidato correcto significaba dotarla conforme con su estatus, caudal e inflado honor familiar. En términos económicos, significaba partir un monto considerable del patrimonio para que lo administrara y disfrutara un foráneo, un candidato de jerarquía equivalente y, a menudo, ajeno al linaje de la novia, que bien podía malversarlo o esfumarlo. De no contraer matrimonio, las doncellas tampoco podían permanecer en el hogar familiar. No obstante ello, existía la posibilidad de acceder a otro matrimonio. Las familias notables podían apelar a un esposo ideal que permanecía como único exponente de otro mercado matrimonial. La alternativa para una doncella de elite era convertirse en esposa de Cristo. Como esposo místico, Cristo requería, mediante sus representantes, menores aportes dotales para formalizar el matrimonio ${ }^{4}$. Por su parte, las esposas de Cristo debían ofrecer castidad, legitimidad de origen, probada genealogía y prestigio social, aunque debían compartir a su consorte, su amor y devoción junto con otras en el claustro (Soeiro 1974, 1978; Reyna 1990; Burns 1999:146).

Así como el matrimonio profano, el sagrado soldaba a los linajes de la elite con otra familia, la conventual, en un lazo tan indisoluble como provechoso (Burns 1999:6). El encomendero Diego de Zárate, a la sazón hermano del licenciado Polo Ondegardo, era el más interesado en la fundación de un convento de monjas en La Plata, en tanto había procreado diez hijos, entre ellos 6 mujeres, la mitad de ellas había decidido depositar en manos de Cristo 5 . 
Frente a la petición de los vecinos de $\mathrm{La}$ Plata, el virrey don Francisco de Toledo, y el rey Felipe II más tarde, autorizaron la fundación de un convento de monjas en La Plata (Calancha 1976 [1639]; III:1177-1181; García Quintanilla 1963; III:145-153; Levillier 1922; II:11-16) ${ }^{6}$. Los años iniciales fueron difíciles, ya que la ayuda financiera real no llegó conforme con lo esperado. El virrey Toledo, ferviente sostenedor de la iniciativa, suspendió la ayuda financiera al enterarse de que el convento platense solamente permitiría el ingreso de doncellas de origen español y descendientes de conquistadores. Siguiendo el consejo de su virrey, Felipe II también resolvió desfinanciar al convento. Reiterando anteriores decisiones, Toledo se negó a patrocinar el convento platense al comprobar su inflexible sesgo racial y clasista, lo que mostraba al heredero de un grande de España más comprensivo que la elite charqueña acerca de la nueva y original situación reproductiva y social de la Colonia. Finalizando el virreinato de Toledo, la firmeza de la elite en limitar los ingresos de doncellas que no pertenecieran a familias notables incrementó la angustia económica que derivó en la suspensión de las obras edilicias del monasterio, lo que motivó la mediación de los oidores de la Real Audiencia de Charcas, quienes en 1581 y tras la petición del doctor Barros de San Millán, se comprometieron con el rey a que un tercio de las doncellas admitidas fueran mestizas (Levillier 1922; II:11-16). Si inicialmente los padres fundadores hubieran accedido al ingreso de doncellas de otros estratos sociales, los fondos hubieran llegado, tal como prometido ${ }^{7}$.

Dejando de lado estas controversias que anclan en el imaginario cultural y social, en esta ocasión nos focalizamos en las tensiones y disputas ocurridas en el claustro, espacio en el que, con diferente grado y trascendencia pública, nacían y pretendían fenecer faltas graves a los votos de castidad, pobreza y obediencia a los que se habían comprometido las monjas. Cuando aludimos al claustro, hablamos de un espacio sagrado y, sobre todo, corporativo en que se llevaban a cabo las prácticas religiosas y en el que no estaban ausentes los vínculos y pasiones profanos, tras los que se mantenía el orden social y los valores establecidos ${ }^{8}$. Señalemos que al convento lo gobernaban una priora o abadesa, secundada por una superiora, asesorada por el conjunto de monjas de velo negro que para tomar decisiones de fuste se reunían en capítulo al son de campana tañida, según un protocolo cuidadosamente diseñado y establecido en el Libro de Reglas. Las autoridades eran electas cada tres años en capítulo al que asistían todas las profesas. Señálese que las mestizas de velo negro podían elegir aunque no eran electas como autoridad, lo que denota las desigualdades que, como en el siglo, se vivían en el claustro9. Además, las monjas contaban con un patrón, un administrador y un mayordomo pertenecientes a los linajes que depositaban a sus doncellas en el cenobio y que, junto con el vicario eclesiástico y los confesores, eran los varones admitidos en el claustro que aconsejaban y velaban por la salud económica y espiritual del colectivo femenino. Las prácticas conventuales, oscilantes entre la vida en reclusión y la cotidianidad mundana, permiten atisbar cómo se ejercía el poder desde el monasterio y de qué forma operaban las redes intraélite que, desde el claustro, se manifestaban en el siglo, lo que se perfila en los episodios que siguen.

\section{Justicia, derecho y corporaciones}

En mayo de 1587, los oidores de la Audiencia de Charcas, licenciados Cepeda, Rodríguez, Lopidana y Mora, intervenían en el Acuerdo para tratar el robo sufrido por una monja de Los Remedios en su celda y aposento. Tras la confusa declaración de un fraile agustino, se apresaba a un indio y a un negro como autores del robo. No obstante ello, el superior de los agustinos, fray Diego Nieto, afirmaba que había sido un fraile de la orden quien cometiera el dolo, para prontamente huir de la ciudad junto con un indio chiriguano de su servicio. De inmediato, los oidores mandaron prender a fray Diego de Mendoza, le tomaron una declaración que deliberadamente omitieron registrar y resumir en el Acuerdo para, rápidamente, acordar la conclusión del delito ${ }^{10}$. En el entretanto, la priora de Los Remedios, doña Isabel Velázquez, y un conjunto de monjas profesas congregadas en capítulo, daban poder a tres procuradores de causas de la Real Audiencia para representarlas en un pleito que trataban con los frailes agustinos, sus custodios espirituales, cuya naturaleza tampoco se daba a conocer ${ }^{11}$. En agosto del mismo año, los oidores trataban acerca de la obediencia de las monjas de Los Remedios a sus guardianes religiosos. Con la sola oposición del licenciado Mora, los oidores Cepeda y Lopidana votaban prescindir de los recoletos y otorgar la obediencia, tal como las monjas proponían, al obispado platense $\mathrm{e}^{12}$. Tras estos crípticos incidentes, 
aparecían otros actores interviniendo y enrareciendo la trama de un hecho incoado entre las religiosas y sus vicarios. Las familias de las monjas, selectos habitantes de la ciudad y el obispado conocían una realidad silenciada y tenida como privada, cual era el comportamiento de las monjas y que alcanzaba "algunas deshonestidades de algunos hombres legos y otras personas", a las que convenía que el tribunal pusiese remedio y castigo. De resultas de ello, los oidores acordaron la visita del monasterio por algún canónigo del obispado que mirase "por la honra y reputación de las monjas" 13 , sugiriendo que a más del robo había otras cuestiones internas que debían resolverse desde fuera del claustro. Más allá de recostarse sobre la Audiencia, y específicamente sobre determinados jueces, las monjas no admitían el ingreso de visitador alguno, mientras continuaban peticionando a los oidores sin acatar sus sentencias.

Poco tiempo después y sin contexto informativo alguno, los oidores Cepeda, Lopidana, Mora y Calderón, acordaban expulsar de la ciudad a un tal Jhoan Vaez, portugués y cirujano de profesión, a fin de salvaguardar "la quietud y honestidad" del monasterio $^{14}$.

Más allá de estas informaciones sutil y deliberadamente recortadas, que aluden a un robo en celda y a la expulsión de un cirujano, y no precisamente por mala praxis, observamos la presencia de extraños no solo en el locutorio o tras las rejas, sino en una celda, el ámbito privadísimo de una religiosa ${ }^{15}$. En el medio, recuperamos otra apelación de las monjas ante la Audiencia pidiendo la libre y pronta elección de sus autoridades que los prelados del obispado, sus nuevos guardianes, habían desautorizado. Nuevamente, peticiones y disidencias cruzadas mostraban el empoderamiento de las monjas, que batallaban en tres frentes: con los agustinos, el obispado y la Audiencia, cuyos oidores dividían votos frente a las manipulaciones de las religiosas, quienes amparaban sus solicitudes en las cláusulas de enclaustramiento de Trento, en la inviolabilidad del claustro y en la autonomía dimanada de sus propias reglas. Así, mientras los oidores Cepeda y Mora hacían lugar a la petición electoral, el licenciado Calderón votaba que "ningún oidor de los dichos señores ni otro vaya al monasterio pues... conforme a la ley, la Real Audiencia no puede entremeterse en ella" 16 . Frente al voto de Calderón, insistieron las monjas en que los oidores Lopidana y Mora, que habitualmente las favorecían, se apersonaran al convento y fueran testigos de la elección. Nuevamente, el licenciado Calderón reiteraba que los oidores no debían asistir junto al Cabildo catedralicio a la emisión de votos, pues la Audiencia carecía de fuerza para intervenir tales eventos ${ }^{17}$.

Sin embargo, más allá de su inmunidad, autonomía y reglas propias, el convento -como integrante de la jurisdicción eclesiástica y sobre todo por haber quedado bajo la supervisión de los canónigos- estaba obligado a abrir sus puertas a un representante del obispado si este ordenara una visita, lo que establecían capítulos de Trento y del Sexto Concilio Limense. Justamente en medio de estas acusaciones y demandas cruzadas, se confirmó la visita general a la diócesis platense, la que se encomendó al chantre del cabildo arzobispal, el Dr. Diego Felipe de Molina. Aunque las visitas generales se dedicaban mayormente a observar la cristianización de los indios, el aprendizaje de las Sagradas Escrituras y la evaluación de la tarea de los doctrineros, el Dr. Molina visitó Los Remedios, como institución dependiente de la sede platense. Permitirle el ingreso demandó meses y arduas negociaciones. Al momento de la visita, continuaba la disputa entre las monjas y sus antiguos custodios espirituales, la que permanecía abierta, siendo dificultosa de conciliar y, hasta ahora, de comprender. En medio de su negativa a ser visitadas, las monjas insistían en haber sido ofendidas en su honor y castidad y llevaban a juicio a los frailes. Frente al máximo tribunal de justicia, los agustinos, a más de tomar distancia de la supervisión de las monjas, se explayaban acerca de aspectos de la vida cotidiana en Los Remedios. Afirmaban que las monjas vivían sin cumplir las reglas, que la mayoría eran mundanas, espiritualmente perdidas, personalmente ambiciosas, egoístas y díscolas ${ }^{18}$. En suma, quienes fueran los guardianes espirituales repudiaban a su rebaño y sus comportamientos. Me pregunto, ¿qué había ocurrido en el convento para generar tamaña declaración de los frailes y la presentación acusatoria de las monjas? No hallé signos de solicitación u otras ofensas sexuales cometidas por los agustinos, sin embargo, sus dichos derivaron en el ingreso del visitador, cuya evaluación fue mucho más impactante, al reportar prácticas degradantes y hechos que no podían tolerarse en un convento, para cuya confirmación requería testigos del capítulo catedralicio. Por su parte, las monjas, determinadas a evitar la inspección, apelaron ante la Audiencia sobre el debido respeto a la clausura. De tantas idas 
y vueltas, resulta evidente que tanto la Audiencia como el Cabildo de la ciudad de La Plata favorecían a las religiosas, siendo factible atisbar, tras esas instituciones, las aceitadas redes familiares que designaban a los curules y presionaban a los oidores con el fin de sostener las demandas de sus monjas, evitar algún escándalo y, desde luego, entorpecer y dilatar la visita que podía visibilizarlo.

Luego de interminables negociaciones, a mediados de 1590 el Dr. Molina encaró, aunque con carácter secreto, la inspección in situ a Los Remedios. Después de permanecer un mes en el claustro, el visitador concluyó que las monjas vivían sin reglas ni orden y, por esta razón, mostraban costumbres inapropiadas. Había inspeccionado y permanecido en los espacios públicos y privados del monasterio, tales como el dormitorio común, las celdas, el locutorio, el coro, las puertas comunicantes y el refectorio, donde probó la relajación de la castidad, la obediencia y la pobreza, votos de obligada observancia. A falta de ingresos suficientes, debido a que se habían comprometido varias dotes pero distaban de ingresar, las monjas vivían en necesidad abrumadora, más allá de la obligada pobreza. La falta de cobertura de las necesidades básicas derivó en que algunas hurtaran comida y robaran valiosos bienes de la sacristía para venderlos en el siglo. Respecto de los votos de género de reclusión y castidad, el Dr. Molina avanzó en describir hechos difícilmente imaginables. Al llegar al convento notó que la priora estaba "preñada", lo que no era una novedad ni la primera vez que ocurría, hecho que resultó en la consternación y escándalo de la comunidad. Soslayando su prejuiciosa descripción de género acerca de que la priora era "fea y pervertida", el Dr. Molina describía toda clase de miserias y malos tratos entre las monjas y sus autoridades, al afirmar que la priora, la abadesa y la superiora explotaban a las demás. La mayoría trabajaba para la minoría, cocinando, tejiendo, bordando y cosiendo a expensas de soslayar rezos y meditación. Algunos de los niños que vivían en el claustro eran hijos de las monjas, cuyos padres hacían fila en torno para verlos, a la vez que participaban en las ceremonias dominicales del monasterio. El visitador informó a las autoridades eclesiásticas acerca de la alteración de las reglas, sobre todo de la falta de disciplina y castidad de cinco monjas, cuyos nombres omitió. A pesar del informe, cuando el capítulo catedralicio y la Audiencia decidieron pronunciar sentencia por las denuncias cruzadas, ambas instituciones fallaron en favor de las monjas que, según el prelado visitador, habían llenado de obsequios y favores familiares a los dignatarios civiles y eclesiásticos, logrando dar fin al proceso. Además, las monjas y sus familias, apoyadas por las autoridades judiciales y religiosas, convinieron en quemar la causa y suprimir todo rastro de la misma ${ }^{19}$.

Hasta aquí la prolija descripción de hechos que conllevan la narrativa secuencial de quien articula sus fuentes junto con el funcionamiento institucional y relacional de las monjas y los diferentes agentes habitantes del siglo. Este excepcional relato bien podría culminar con adecuadas conclusiones desde la historia social o de la familia y ponderar las prácticas de las monjas y sus aliados como transgresoras, elitistas y obscenas en el marco de un sistema de gobierno autárquico, nepótico, jerárquico y hasta prebendario que distan de proveer una adecuada hermenéutica a las prácticas de las religiosas, sus familias, el visitador eclesiástico, los oidores y demás agentes involucrados. Cierta literatura que da cuenta de la cultura jurídica europea nutriéndose del imaginario social y de la organización del poder de la monarquía católica, en la que incluyo a su extensión colonial (Hespanha 1994: 63-100, 1998: 58-68), me acercó respuestas a los interrogantes despertados por los varios retazos judiciales recuperados y prendidos al cañamazo institucional, lo que derivaba en preguntarme por la vigencia de la justicia, la organización del poder y su palmaria parcelación que, sin dudas, se correspondía con la construcción corporativa de la sociedad y del mismo convento.

La sociedad colonial, réplica de la metropolitana, se concebía metafóricamente como un cuerpo de múltiples órganos que articulaban su funcionamiento en pos de la armonía del todo. Esos órganos configuraban diferentes centros autónomos de poder que se sistematizaban en varios niveles. Así, cuerpos tales como familia, comunidades o corporaciones, moviéndose en su autonomía, aluden a la pluralidad del poder, los varios universos institucionales y las limitaciones de la autoridad de la Corona frente a los derechos particulares establecidos (Clavero 1989:586, 588; Hespanha 1996:21-23). Lo expuesto anclaba en una ideología social y política que sostenía la existencia de un orden universal que amparaba tanto a los hombres como a las cosas y se orientaba a un objetivo único, el bien común, identificado con el mismo Creador (Hespanha 1998:59). Ese orden se estructuraba en el equilibrio jerárquico y vincular de 
las personas y sus prácticas diferenciales conformes a su estado. Valga señalar que nada más lejos en la sociedad premoderna que la individuación, valor pertinente al monarca, a la monarquía católica que, aunque entera y única, se replicaba y desdoblaba, en algún caso de manera clónica como en la institución Audiencia, cuyas sentencias y provisiones procedían o dimanaban del rey. Por persona se entendía, entonces, una posición, estado o estatus en el que se concentraba la autoridad o potestad (Hespanha 1996:21; Clavero 2006:1). Porque si bien el Creador había hecho a los hombres y las cosas, la armonía reinaba en torno a la jerarquía de cada quien en el todo (Clavero 1986).

En ese orden, la Audiencia de Charcas, como todo tribunal, era la monarquía activada en el colectivo de su colegiatura y, por tanto, dispensaba justicia por delegación, por clonación con la monarquía, de manera que le competía garantizar justicia, de modo alguno mediante un único derecho, sino el de cada cual, el de cada cuerpo social o corporación ligada a un estatus o estado determinado (Clavero 2006:1-4). La realización de la justicia era asimismo política, de manera que los jueces debían garantizar el gobierno y el derecho de cada cual en el cuerpo social. O sea que, los oidores, como oídos del rey, escuchaban los reclamos de partes, en este caso de la corporación convento, garantizando una justicia que, en los términos descriptos, se resumía en atribuir a las monjas $s u$ derecho, el de $s u$ persona conforme con su estatus dentro de la sociedad estamental. Así, el convento, en su carácter comunal o corporativo, tenía capacidad judicial propia en el ejercicio de jurisdicción. Como lo tenía la Iglesia, las órdenes militares y demás estados de la monarquía católica (Clavero 2006:5). De manera que cada corporación $\mathrm{u}$ orden, en una suerte de ritual con final aproximadamente cierto y fundado, situado en su cuota relacional y social, demandando justicia unos y manteniendo el orden otros en sus múltiples niveles, armonizaban y, frente a una crisis, readecuaban el necesario equilibrio de las partes. Una de ellas, el convento, no era solo un cuerpo autónomo sino la cáscara densa y corporativa de muchas casas pobladas, las de la elite, y una síntesis poderosa de ellas. Los pater familias debían velar por su parentela pero sobre todo mostrar éxito en el gobierno de sus casas y, especialmente, ejercer autoridad sobre sus mujeres, quienes no solo concentraban la honra del linaje sino que por su condición de género escapaban a la garantía y control de la justicia y necesitaban tutela permanente. De manera tal que resulta atendible que los patriarcas amparasen a sus propias mujeres, las monjas de Los Remedios, que habitaban en una suerte de casa unificada de las muchas casas de la elite. Ello remite a la fortaleza de la organización doméstica, al ejercicio de un patriarcado cuya autoridad alcanzaba a todos los integrantes de la casa, familiares o no, allegados y dependientes, agentes y clientes, cuyo orden era jurídico, a más de jerárquico, preceptivo y normativo (Hespanha 1996:22-25; Zamora 2017:112-115).

¿Cómo pensar, sino como estrategia de reafirmación de poder, las reiteradas presentaciones y apelaciones de las monjas frente a corporaciones como la audiencia, el obispado y el cabildo? Con el sostén ideológicamente compartido de esos cuerpos afines, las decisiones resultaban favorables y los planteos lograban adquirir mayor firmeza. Y, sobre todo, otorgar justicia y sentencia favorable a Los Remedios, se matizaba con dones y regalos que hacían a la misma generación de la justica, que respondía con el contra don de declaraciones secretas, la dilación y quema de los procesos o los resultados sintéticos y opacos de una visita lesiva para el honor de la corporación convento, cuya esencia jerárquica y de valores debía, más allá de sus prácticas, resguardarse para contribuir a la estabilidad del sistema (Clavero 2006:8-9). Valores específicos como el honor, la honestidad, la verdad y la bondad son acreencias de nobles, prelados y togados, de allí que la falsedad y todos sus sucedáneos resultaran condenables (Hespanha 1996:61-62). Sin embargo, estimo que la omisión y la supresión informativa, como detectáramos tanto en las apelaciones de las monjas como en los acuerdos de los oidores o en la misma visita eclesiástica, eran parte de la llamada cultura del simulacro o disimulo imperante entre las elites y, aparentemente, menos condenable que la mentira (Hespanha 1994:65; 1998:62). Más allá de que en el siglo XVII habrá una reacción a esta práctica del embuste y el engaño, sin apelar a ella las monjas no hubiesen podido travestir o eludir sus comportamientos inapropiados. En términos de Bourdieu (1980:52-65), ciertas monjas desafiaron el habitus mediante prácticas y estrategias individuales que, por su magnitud, redundaron en una agencia de representación colectiva a la que arrastraban a su corporación y otras afines.

Para finalizar, más allá de considerar a un monasterio de monjas una ciudad dentro de otra y al enclaustramiento como un imperativo de género 
que se proponía asegurar la castidad femenina, Los Remedios, como parte, segmento, corporación o estado del cuerpo de la monarquía católica, no escapó en sus valores, jerarquías y normas a la concentración del don, la liberalidad y la gratitud como cimientos ideológicos de las redes relacionales e institucionales que hacían a la armonía del sistema.

\section{Agradecimientos}

Esta investigación comenzó en 2017 durante mi residencia en el Internationalen Kolleg Morphomata de la Universität zu Köln, Alemania. Las fuentes citadas se recolectaron durante décadas con la financiación del CONICET, la Universidad de Buenos Aires y la Agencia de Promoción Científica y Tecnológica de la República Argentina. Una versión preliminar de este ensayo se presentó en el Coloquio Internacional "Cultura gubernamental y jurídica, actores políticos y redes de poder en el centro sur andino, S.XVI-XVII", celebrado en Santiago de Chile, 11 y 12 de junio de 2019 y organizado por la Universidad Bernardo O'Higgins en el marco del Convenio que vincula a esa institución con la Facultad de Filosofía y Letras de la UBA y su Instituto de Historia Argentina y Americana "Dr. Emilio Ravignani", unidad ejecutora de doble dependencia UBA-CONICET.

\section{Referencias Citadas}

$\mathrm{AACh}$

2007 Acuerdos de la Real Audiencia de La Plata de los Charcas, 1588-1635. 2007. Vols. II-IV. Sucre: Corte Suprema de Justicia, Archivo y Biblioteca Nacionales de Bolivia, Embajada de España en Bolivia, Agencia Española de Cooperación Internacional.

ABNB EP

Archivo y Biblioteca Nacionales de Bolivia, Escrituras Públicas AGI

Archivo General de Indias

Atienza Hernández, I.

1990 "Pater familias, señor y patrón: Oeconomía, clientelismo y patronato en el Antiguo Régimen". En Relaciones de poder, de producción y parentesco en la Edad Media y Moderna, compilado por R. Pastor, pp. 411-458. Consejo Superior de Investigaciones Científicas, Madrid.

Barnadas, J. M.

1973 Charcas 1535-1565. Orígenes históricos de una sociedad colonial. CIPCA, La Paz.

Berríos, J. D.

1909 Clausura de Monasterios y Conventos. Tipografía "La Patria", La Paz.

Bestard Camps, J.

1992 "La estrechez del lugar. Reflexiones en torno a las estrategias matrimoniales cercanas". En Poder, familia y consanguinidad en la España del Antiguo Régimen, editado por F. Chacón Jiménez y J. Hernández Franco, pp. 107-156. Anthropos, Barcelona.

Bourdieu, P.

1980 The Logic of Practice. Stanford University Press, Stanford.

Burns, K.

1999 Colonial Habits. Convents and the Spiritual Economy of Cuzco, Peru. Duke University Press, Durham.

Calancha, Fray A. de la

1976 [1638] Crónica Moralizada del Orden de San Agustín en el Perú. Editado por I. Prado Pastor, 6 Tomos, Universidad Mayor de San Marcos, Lima.

Chacón Jiménez, F. y J. Martínez López

1990 "La historia de la familia en España durante la Edad Moderna. Notas para una reflexión metodológica”. En
Historia Social de la Familia en España. Aproximación a los problemas de familia, tierra y sociedad en Castilla (ss. XV-XIX), editado por F. Chacón Jiménez, pp. 31-44. Instituto de Cultura Juan Gil Albert, Alicante.

Clavero, B.

1986 Tantas personas como estados. Por una antropología política de la historia europea. Tecnos, Madrid.

1989 "Del estado presente a la familia pasada (a propósito de estudios acerca de la Famiglia Aristocratica así como también de la Familia Mediterránea)". Quaderni Fiorentini per la storia del pensiero giuridico moderno 18: 583-605.

2006 "Justicia y Gobierno, Economía y Gracia". En Real Chancillería de Granada: V Centenario (1505-2005), editado por J. Moya Morales, E. Quesada Dorador y D. Torres Ibáñez, pp. 1-13. Junta de Andalucía, Granada.

Comas d'Argemir, M. D.

1992 "Matrimonio, patrimonio y descendencia. Algunas hipótesis referidas a la Península Ibérica". En Poder, familia y consanguinidad en la España del Antiguo Régimen, editado por F. Chacón Jiménez y J. Hernández Franco, pp. 157-175. Anthropos, Barcelona.

Ferreiro, J. P.

2003 "Parentesco y estructuras familiares en Jujuy, siglos XVII-XVIII". En Familia, Parentesco y Redes Sociales, compilado por C. del C. López, pp. 67-100. REPHoS, Instituto de Estudios Geográficos, Universidad de Tucumán, Tucumán.

García Quintanilla, Mons. J.

1965 Historia de la Iglesia de los Charcas o La Plata (Sucre, Bolivia), Tomo II, Editorial Don Bosco, Sucre.

Hespanha, A. M.

1994-1995 "Las categorías de lo político y de lo jurídico en la época moderna". Revista Interdisciplinar de Estudios Histórico-jurídicos, 3-4: 63-100.

1996 "Una nueva historia política e institucional". Revista Mexicana de Ciencias Políticas y Sociales, 41, No. 166:9-38.

1998 Cultura Jurídica europea. Síntesis de un milenio, Tecnos, Madrid.

Lavrin, A.

2014 "La educación de una novicia capuchina". Hispanófila 171:77-93. 
2008 Brides of Christ. Conventual Life in Colonial Mexico. Stanford University Press, Stanford, Ca.

Levillier, R.

1922 LaAudiencia de Charcas. Correspondencia de Presidentes y Oidores. Tomo II. Imprenta de Juan Pueyo, Madrid.

Lockhart, J.

1968 Spanish Peru 1532-1560. A Colonial Society. The University of Wisconsin Press, Madison.

Martínez, M. E.

2008 Genealogical Fictions. Limpieza de Sangre, Religion, and Gender in Colonial Mexico. Stanford University Press, Stanford, Ca.

Presta, A. M.

1997 "Detrás de la mejor dote, una encomienda. Hijas y viudas de la primera generación de encomenderos en el mercado matrimonial de Charcas, 1534-1548". Revista Andes 8: 27-46.

2000 Encomienda, familia y negocios en Charcas colonial. Los encomenderos de La Plata, 1550-1600. Instituto de Estudios Peruanos-Banco Central de Reserva del Perú, Lima.

2008 "Entre la vara y los indios: la sociedad de Charcas frente a parejas imposibles (1560-1580)". Allpanchis 71:113-139.

2013 "El Charcas de Josep M. Barnadas y su recepción e influencia en la historiografía argentina". Anuario de
Estudios Bolivianos, Archivísticos y Bibliográficos 18. Archivo y Biblioteca Nacionales de Bolivia: 103-122.

Recopilación de las leyes de los Reynos de las Indias. Mandadas a imprimir y publicar por la Magestad Católica del Rey Don Carlos II. 1841. Tomo Primero. Quinta Edición. Boix Editor, Madrid.

Reyna, M. del C.

1990 El Convento de San Jerónimo. Vida Conventual y Finanzas. Instituto Nacional de Antropología e Historia, México.

Soeiro, S.

1974 "The Social and Economic Role of the Convent: Women and Nuns in Colonial Bahia, 1677-1800". The Hispanic American Historical Review, Vol. 54, No. 2 (May, 1974): 209-232.

1978 "The Feminine Orders in Colonial Bahia, Brazil. Economic, Social and Demographic Implications, 16771800". En Latin American Women: Historical Perspectives, editado por A. Lavrin, pp. 173-197. Greenwood Press, Westwood, Conn.

Zamora, R.

2017 Casa poblada y buen gobierno. Oeconomía católica y servicio personal en San Miguel de Tucumán, siglo XVIII. Prometeo libros, Buenos Aires.

Notas

1 AGI (Archivo General de Indias) Charcas 78, N² 24; AGI Charcas 418, L. 1; Fray Antonio de la Calancha 1976 [1657]: III, 1177-1179; Mons. Julio García Quintanilla: 1963, III: 147-153.

2 La casa poblada era la residencia principal de un encomendero, habitada por cantidad de familiares, agentes, clientes, esclavos e indios de servicio a quienes el señor mantenía o "daba de comer". En ella se concentraba el ideal señorial junto con las ambiciones y deberes militares y sociales del encomendero (Lockhart, 1968: 21). La casa poblada refiere a la "casa grande" (Atienza Hernández, 1990: 413-416), réplica de las jerarquías y valores sociales que por su organización política y patrimonial constituyó "una analogía del reino". La casa poblada es, asimismo, un instituto jurídico colonial reflejo de la cultura señorial en su concreción del ideal de gobierno y familia al exhibir el conjunto de las prácticas políticas, públicas y privadas de un señor y sus dependientes, parientes y subordinados aún en territorios marginales de la Colonia (Zamora 2017: 107-129). Se la asume también como el núcleo ampliado de parentesco real o simbólico, siendo la casa la entidad que concentra la sangre y la tierra y reproduce la dominación y la sociedad colonial en un espacio acotado (Ferreiro, 2003: 67).

3 Se trata de don Gabriel Paniagua de Loaysa, encomendero de Mizque, don Bernaldino de Meneses, quien recibiera la merced de yamparaes, y don Fernando de Zárate, encomendero consorte de Tapacarí (Presta: 1997; 2000; 2008).

4 Mientras que entre 1574 y 1620 las dotes de las monjas de velo negro o de coro ascendían a 1500-2000 pesos ensayados, las de las doncellas de la elite casadas en el siglo oscilaban entre los 10 y 40 mil pesos ensayados. Doña Juana de Herrera y Sotomayor llevó en dote 32.000 al casarse con el encomendero Rodrigo de Orellana, doña Ana Cabrera de Córdoba, hija de Hernán Cabrera de Córdoba tenedor de indios en el pueblo de Colpavilque y minero de Potosí, recibió 40.000 al matrimoniar con Juan Porcel de Padilla, mientras que doña Ana Verdugo de Loaysa, hija del encomendero de Mizque don Gabriel Paniagua de Loaysa, recibió 30.000 pesos ensayados al casarse con don Vasco de Escobar Manrique, encomendero del Cuzco, véase ABNB EP (Archivo y Biblioteca Nacionales de Bolivia, Escrituras Públicas) 7 Lázaro del Águila - La Plata, 20.9.1565, fs. ccii $r$ - ccvii v, ABNB EP Vol. 62 Philippe de Godoy - La Plata, 12.7.1609, 4fs, s/f, ABNB EP Vol. 81 Alonso Fernández Michel - 31.8.615, fs. 605-606v.

5 ABNB EP 19 Juan García Torrico - La Plata, 5.7.1582, f. $660 \mathrm{v}$.

6 AGI Charcas 418, L. 1, 161v. Registro de oficio y partes para la Audiencia de Charcas; AGI Charcas 31.

7 Cf. Burns: 1999, 37. Por similares motivos, Toledo había desafiado previamente al Cabildo de Cuzco cuando los padres fundadores pretendieron que exclusivamente las monjas de velo negro y, entre ellas, las de probada legitimidad y ascendencia genealógica, fueran las abadesas o superioras en detrimento de las restantes monjas, las que de modo alguno eran elegibles como autoridades. La posible reiteración de tales discriminaciones fue la que motivó que el rey Felipe II legislara sobre el particular, "[...] Y si algunas mestizas quisieren ser religiosas y recibidas al hábito y velo en los monasterios de monjas, provean que no obstantes cualesquiera constituciones, sean admitidas en 
los monasterios y á las profesiones, precediendo la misma información de vida y costumbres". Recopilación, Tomo I, Libro I, Tit. 7, Ley 7: D. Felipe en San Lorenzo á II a 31 de agosto y 28 de septiembre de 1588, p. 57.

8 Numerosos estudios presentan a los claustros como espacios de desarrollo de las artes y humanidades, ya que las monjas, como miembros de la elite, eran letradas, educadas en música, letras y artes, aunque en ese medio no todas las prácticas eran ejemplares ni solidarias, Cf. Lavrin: 2014, 77-93.

9 Constituciones formadas para el régimen y gobierno de las religiosas del Monasterio de Nuestra Señora de los Remedios de esta ciudad de La Plata. Libro de Reglas original. Agradezco al padre Bernardo Gantier sj quien me permitió la consulta del libro manuscrito.

10 ARACh (Acuerdos de la Real Audiencia de La Plata de los Charcas) III, jueves 30.4.1587, 510.
11 ABNB EP 39 Gerónimo de Porres - La Plata, 3.9.1587, fs. 2237-2239.

12 ARACh IV, Lunes 31.8.1587, 525; ARACh IV, lunes 8.2.1588, 15.

13 ARACh IV, lunes 19.9.1588, 99.

14 ARACh IV, lunes 30.1.1589, 140.

15 Aunque sin aparente relación con estos episodios, en 1583 había ocurrido el ingreso de dos hombres al convento, uno de estos había deshonrado a una monja, ARACh III, jueves 26.9.1583, 394.

16 ARACh IV, miércoles 10.5.1589, 169

17 ARACh IV, viernes 12.5.1589, 169.

18 AGI Charcas 143. Visita al Obispado de Charcas, 1590, f $6 r$.

19 AGI Charcas 143. Visita al Obispado de Charcas, 1590, fs. $6 \mathrm{v}-7 \mathrm{r}$. 